\title{
A bispecific aptamer sensor towards T-cell leukemia detection in the tumor microenvironment
}

Natalie Boykoff ${ }^{2}$, Lina Freage ${ }^{1}$, Jared Lenn ${ }^{4}$, and Prabodhika Mallikaratchy ${ }^{1,2,3^{*}}$.

${ }^{1}$ Department of Chemistry, Lehman College, The City University of New York, 250 Bedford Park Blvd., West, Bronx, NY 10468, USA

${ }^{2}$ Ph.D. Programs in Chemistry and Biochemistry, CUNY Graduate Center, 365 Fifth Avenue, New York, NY 10016, USA

${ }^{3}$ Ph.D. Program in Molecular, Cellular and Developmental Biology, CUNY Graduate Center, 365 Fifth Avenue, New York, NY 10016, USA

${ }^{4}$ The Bronx High School of Science, 75 W 205 ${ }^{\text {th }}$ Street, Bronx, NY 10468

*To whom correspondence should be addressed: Prabodhika Mallikaratchy, Department of Chemistry, Lehman College, The City University of New York, 250 Bedford Park West, Bronx New York, NY 10468;

prabodhika.mallikaratchy@lehman.cuny.edu; Phone: 347-577-4082. 


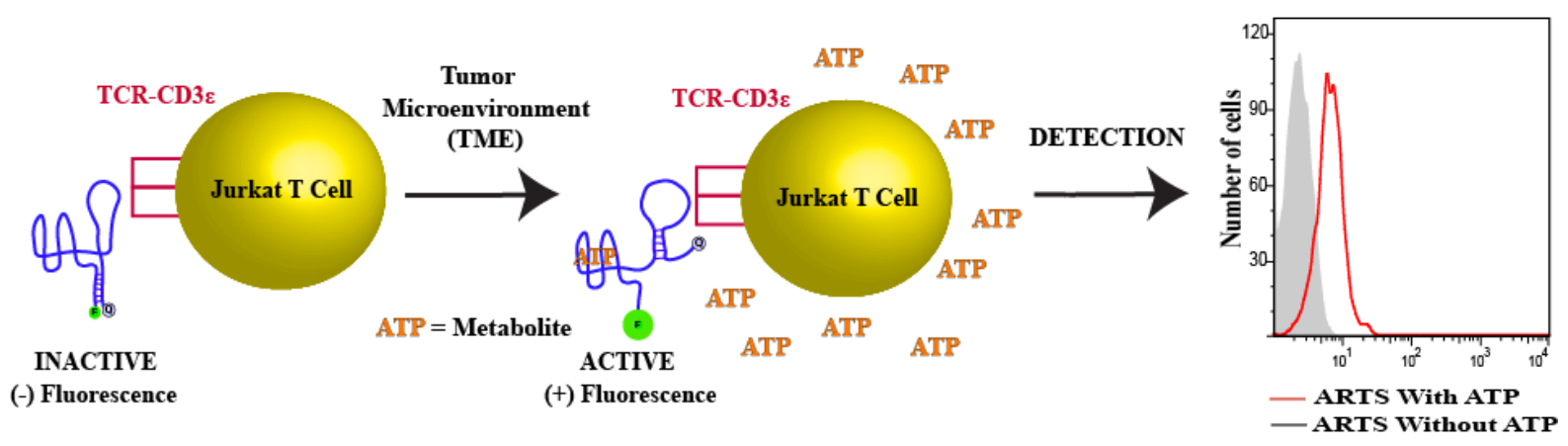

TOC schematic presentation of ARTS (ATP-Regulated-T-Cell Sensor).

A bispecific aptamer molecule that performs as a dual detection platform and detects cells only when a given metabolite concentration is elevated in the Tumor-MicroEnvironment. 


\section{Abstract:}

The current detection methods of malignant cells are mainly based on the high expression levels of certain surface proteins on these cells. However, many of the same surface marker proteins are also expressed in normal cells. Growing evidence suggests that the molecular signatures of the tumor microenvironment (TME) are related to the biological state of a diseased cell. Exploiting the unique molecular signature of TME, we have designed a molecular sensing agent consisting of a molecular switch that can sense the elevated concentration of a small molecule in the TME and promote precise recognition of a malignant cell. We accomplished this by designing and developing a bispecific aptamer that takes advantage of a high concentration of ATP in the TME. Thus, we report a on a prototype of a bispecific aptamer molecule, which performs as a dual detection platform and recognizes tumor cells only when a given metabolite concentration is elevated in the TME. This system overcomes hurdles in detecting tumor cells solely based on the elevated expression of cell surface markers, providing a universal platform for tumor targeting and sensing. 


\section{Introduction:}

Unlike normal cells, malignant cells sustain their rapid anabolic and energy production rates by requiring extraordinary high levels of nutrients. ${ }^{1-3}$ This altered metabolic state of tumor cells and their interaction with the surrounding tissues form a unique microenvironment termed tumor microenvironment or TME. ${ }^{4}$ The biochemical composition of the TME is based on the survival of tumor cells and their need to mitigate the competition for nutrients by surrounding cells. ${ }^{3,5}$

Additionally, the unique chemical signatures of the TME could characterize the tumor cell's own metabolic needs and waste products as a reflection of their biological state.1${ }^{7}$ The TME also assists tumor cells in escaping immune surveillance, orchestrating a remarkable ability to adapt and survive ${ }^{6,7}$ Accordingly, the detection and modulation of the TME's biochemical composition could be an exciting avenue for tumor-targeting owing to its prominent role in the initiation and survival of tumors. ${ }^{8-10}$ The TME is characterized by abnormal fluctuations, including hypoxia (low oxygen levels), low extracellular $\mathrm{pH}$ (ranging from 6.5-6.8) resulting from the upregulation of glycolysis, and atypical expression of tumor-related enzymes. ${ }^{11,} 12$ Recently, the ATP concentration was found to be 1000 to 10,000 times higher within the TME than that of the typical cellular environment, indicating that the concentration of ATP can be utilized as a secondary biomarker to detect tumor cells. ${ }^{7}, 13$

So far, cell-surface molecular signatures of diseased cells have been the focal point for the design and engineering of diagnostic and therapeutic targeting molecules against tumor cells. ${ }^{14-16}$ Indeed, a cell's pathological state is highly correlated to elevated expression levels of particular molecular signatures on the cell surface. However, many of these same surface marker proteins are also expressed in normal cells leading to higher background signals. ${ }^{17}$ Consequently, significant research efforts are now centered on detecting altered cellular pathological states using molecules secreted by malignant cells, such as exosomes, microRNAs, proteins, and other metabolic molecules unique to the tumor cell's metabolic states. ${ }^{17-20}$ The primary biomarker protein-related tumorigenesis and the unique metabolic state of TME can be utilized as a secondary marker to enhance the specificity of detection. Thus, we herein sought to explore the utility of the TME's unique chemical signature as an avenue to detect tumor cells and their elevated protein expression specifically. We accomplished this by designing a bispecific aptamer with one arm towards a highly 
expressed tumor-related metabolite ATP and the other arm towards a cell surface marker expressed on human T-cell lymphoma. ${ }^{21,22}$ Thus, the functional bispecific aptamer molecule, described here, effectively combines two molecular signatures related to a disease state, namely, altered ATP concentration in TME and an elevated expression of the cell surface marker TCR-CD3 $\varepsilon$ in T-cells.

This prototype bispecific sensor model is termed ATP-Regulated T cell Sensor

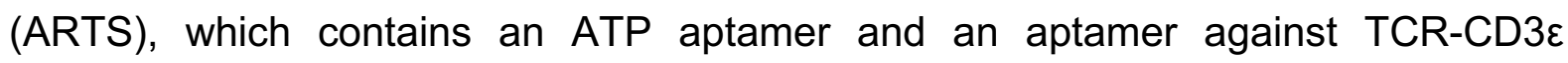
expressed on T-cells. The ARTS molecule is designed to sense the elevated concentration of ATP in the TME, which then subsequently undergoes a conformational switch, allowing the tumor-specific arm of the bispecific aptamer to bind to the CD3+ $T$ cell leukemia by targeting through the TCR-CD3E receptor (Scheme 1). By combining two aptamers, we, demonstrate that a bispecific sensor molecule with dual specificity can serve as a superior detection platform that can recognize diseased cell states with higher precision.

\section{Results and Discussion:}

The bispecific aptamer consists of a G-quartet quadruplex ATP aptamer and an antiCD3 $\varepsilon$ aptamer linked with two tandem units of Hexa-ethylene glycol spacer (6 repeats, 24 carbon spacer). Each terminus is labeled with a fluorophore and a quencher. ARTS detects T-cells only when a high concentration of ATP is present, facilitating the enhanced dual specificity in T-cell lymphoma detection in TME. 
ATP-Aptamer

I) 5'-6FAM-CACCT $G G G$ GGAGTATTGCGGAGGAAGG-(PEG)-AA

TGGGCGGGGTGGGTCTAGTGTGGATGTTTAGGGGGCCCAGGTG-IBFQ-3'

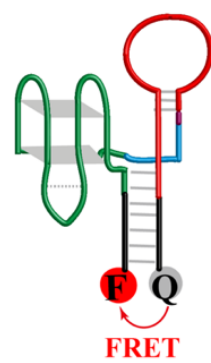

State A Anti-CD3\&-Aptamer

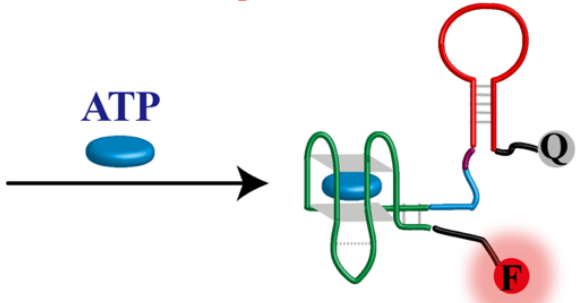

State B

Random Sequence

II) 5'-6FAM- $C A C C A C A G$ ATTTATAATTTTTTATAATAAT-(PEG)-AA

TGGGCGGGGTGGGTCTAGTGTGGATGTTTAGGGGGCTGTGGTG--IBFQ-3'

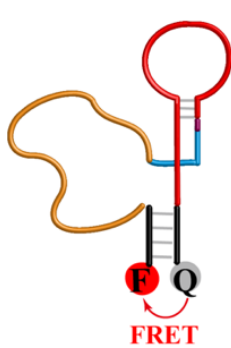

State A Anti-CD3E-Aptamer

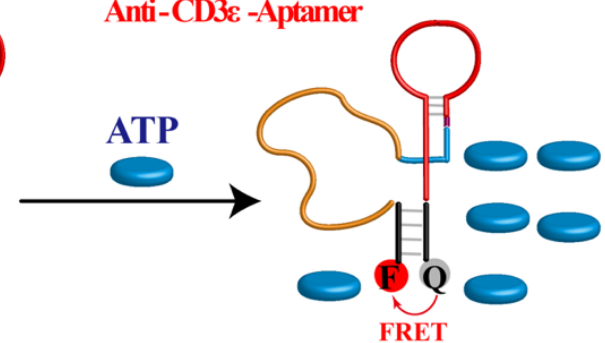

State A

ATP-Aptamer

III) 5'-6FAM-CACCTGGG GGAGTATTGCGGAGGAAGG-(PEG)-AT CGATCTTACAATCATCATC TCT ATG CTAAG CG CGG CCCAGGTG-IBFQ-3' Random Sequence

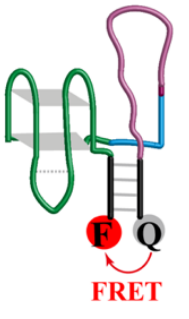

State A

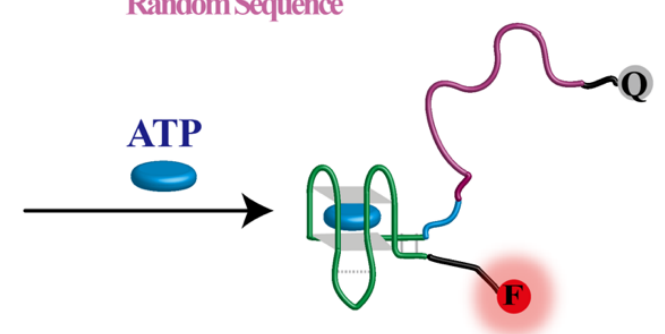

State B

Scheme 1: Design of the bispecific aptamer, facilitating a conformational change from state A to state B. I) ATP-Regulator T Cell-Sensor (ARTS), II) Control-1 with

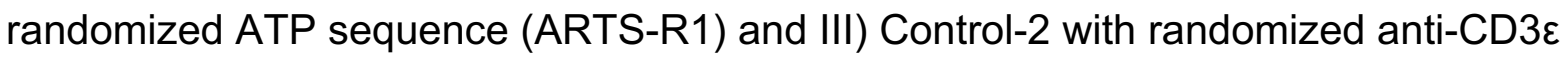
aptamer (ARTS-R2). All three molecules possess 6-Carboxyfluorescein (6-FAM) and lowa Black Fluorescence Quencher (IBFQ) on their 5' and 3' ends, respectively. State $A$ is stable in the absence of the ATP; i.e., in this state, the duplex structure is stable, and the two reporting molecules, 6-FAM and lowa Black, are in close proximity, enabling fluorescence energy transfer (FRET). State $B$ shows the open conformation, which is triggered by the presence of ATP molecules, allowing the

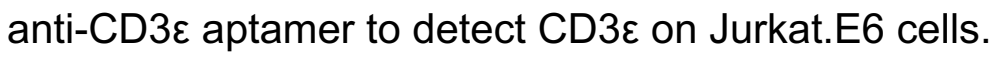


The ARTS design consists of two states. State A consists of an inactive anti-CD3ع aptamer and an ATP aptamer arranged such that the functional folds of both aptamers are disrupted to form a stable duplex (Scheme 1-I), bringing the fluorophore and the quencher in close proximity, resulting a quenched fluorescence.

In state $\mathrm{B}$, this duplex between the two aptamers can be destabilized through a conformational switch induced by ATP binding to ATP aptamer, simultaneously generating a fluorescence signal while, at the same time, releasing the primary

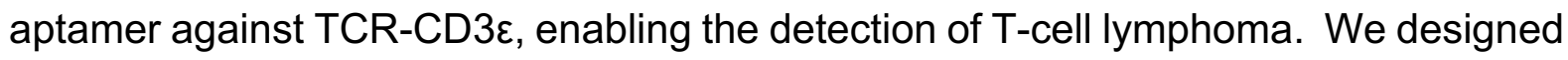
two control molecules for this bispecific aptamer. The first control molecule randomizes the ATP aptamer. Termed ARTS-R1, this controller prevents the conformational switch of the ATP aptamer in the presence of ATP (Scheme 1-II). The second controller, termed ARTS-R2, randomizes an anti-CD3E aptamer (Scheme 1III). Under the control of ARTS-R2, the binding of ATP to the ATP aptamer leads to a conformational switch promoting State $B$, as described above. However, although the fluorescence is increased, the anti-CD $3 \varepsilon$ detection on T-cell lymphoma is not possible. We first evaluated the thermal stability of ARTS by measuring the fluorescence intensity of the FAM fluorophore as a function of temperature. Below the melting point, ARTS forms a stable duplex structure (State A), leading to no detectable fluorescence signal in the system (Figure 1A-C). However, while the ARTS duplex structure is stable at temperatures well below its melting temperature at $75.2^{\circ} \mathrm{C}$, the gradual increase of temperature beyond melting point leads to a disruption of each aptamer's duplex structure, generating single-stranded DNA (Figure 1A-C). These results show the high thermostability of ARTS in physiological temperature.
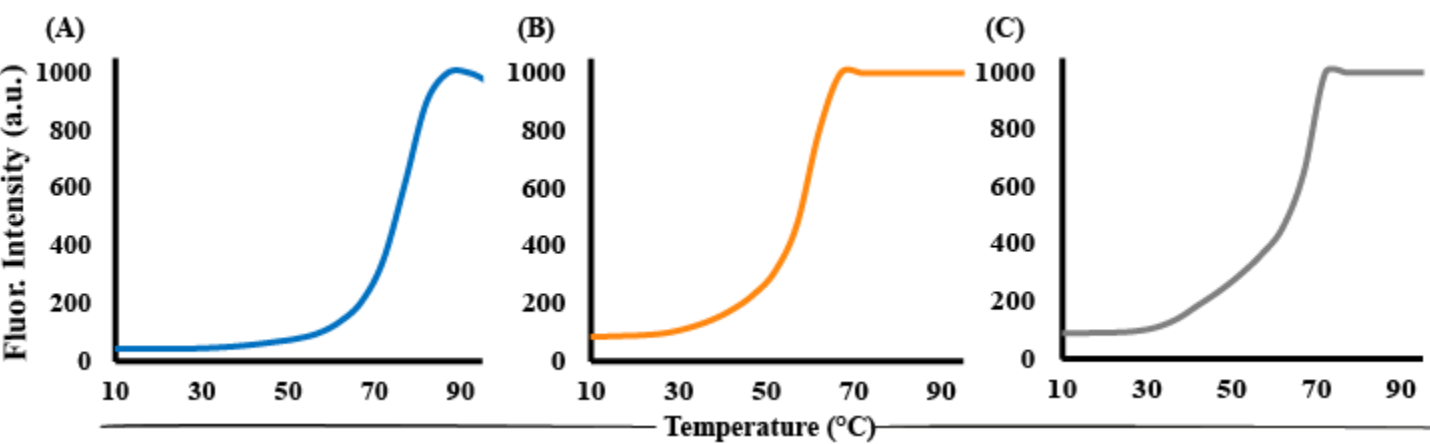

Figure 1: Thermal stability analysis as measured by fluorescence intensity as a function of temperature. A) ARTS, B) ARTS-R1 and C) ARTS-R2 at different temperatures. 
Next, the sensitivity of ARTS was analyzed as a function of the concentration of ATP (Figure 2A). The experiments were conducted using a fixed concentration of ARTS at $250 \mathrm{nM}$ in Tris-HCl Buffer $(10 \mathrm{mM}, \mathrm{pH}=8.4)$ and $6 \mathrm{mM} \mathrm{MgCl}$. The initial baseline fluorescence signal was indicative of state A (absence of ATP), which was first recorded. Then ATP was added in a stepwise manner at 0.5, 1, 1.5, 2, 2.5, 3, 3.5, and $4 \mathrm{mM}$ concentrations. The fluorescence signal increased immediately after the addition of $0.5 \mathrm{mM}$ ATP, indicating that the addition of ATP leads to a conformational switch (Figure 2A). The subsequent addition of ATP further increased the fluorescence signal saturating at a concentration of $3.5 \mathrm{mM} \mathrm{ATP}$, presenting a linear relationship between fluorescence enhancement and ATP concentration that resulted from the conformational switch (Figure 2B). The controls were also tested with different concentrations of ATP. As anticipated, the fluorescence intensity of ARTS-R2 increased as a function of ATP concentration in a manner similar to that of ARTS. In contrast, no significant change in fluorescence signal was observed for ARTS-R1 in the absence or presence of ATP, demonstrating the sensitivity and the specificity of conformational switch in response to the presence of ATP (Figure S-1 and S-2).
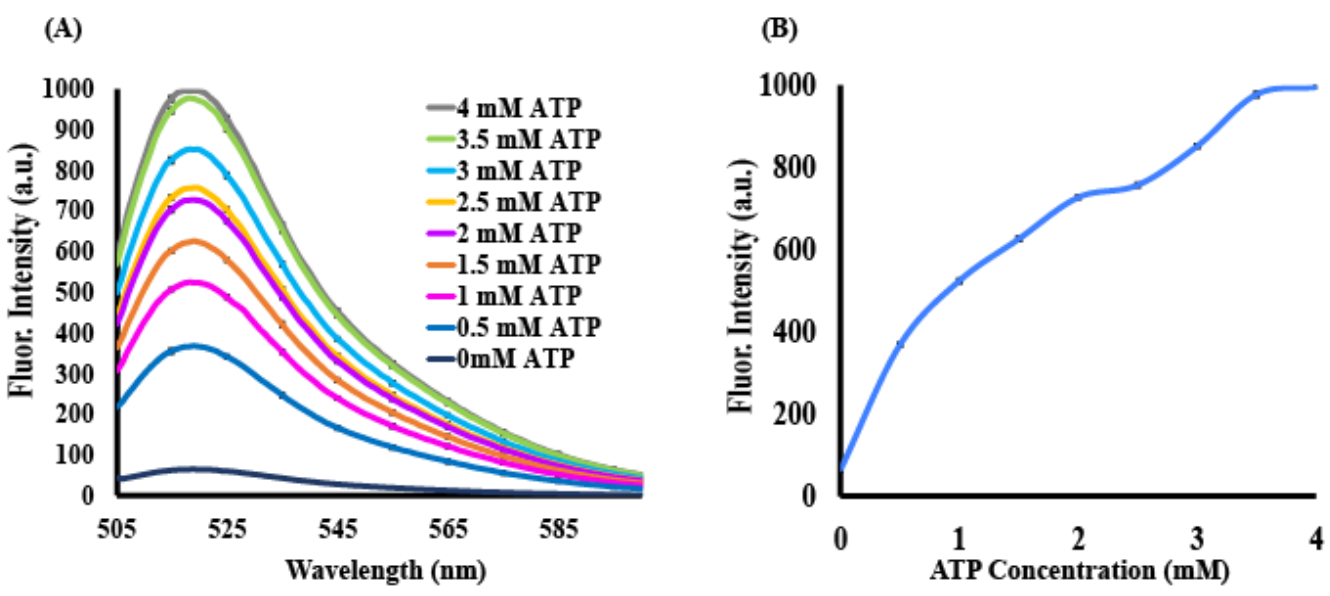

Figure 2: Change of fluorescence intensity of ARTS as a function of ATP concentration. (A) Fluorescence spectrum of ARTS in the absence of ATP and with $0.5,1,1.5,2,2.5,3,3.5$ and $4 \mathrm{mM}$ of ATP; (B) Titration plot of ATP incubated with ARTS over the range of $0-4 \mathrm{mM}$ ATP. The ARTS was prepared for the assay by heating at $95^{\circ} \mathrm{C}$ for 5 mins and then cooling down to $25^{\circ} \mathrm{C}$ for 30 minutes. Nine samples of 250nM ARTS and different concentrations of ATP were prepared in a 
final volume of $500 \mu \mathrm{L}$ of Tris-HCl Buffer (10 mM, $\mathrm{pH}=8.4)$ and $6 \mathrm{mM} \mathrm{MgCl}_{2}$, followed by placing in a Cary Eclipse fluorescence spectrophotometer at $25^{\circ} \mathrm{C}$.

Fluorescence spectra were produced with an error $= \pm \sim 2$.

We next examined the sequence specificity of the conformational change induced by ATP using $250 \mathrm{nM}$ of ARTS, ARTS-R1, or ARTS-R2 in Tris-HCl Buffer (10 mM, $\mathrm{pH}=8.4)$ and $6 \mathrm{mM} \mathrm{MgCl}$. After recording the background fluorescence of ARTS in the absence of ATP, 2 mM ATP were added. As expected, ARTS-R1 showed no change in fluorescence in the presence of ATP compared to ARTS (Figure 3A-B). In contrast, ARTS-R2 with randomized anti-CD3 $\varepsilon$ aptamer did undergo a conformation change in the presence of ATP, leading to an enhanced fluorescence signal (Figure $3 C)$, confirming that the CD3e-specific DNA sequence does not affect the conformational change of the ATP aptamer.
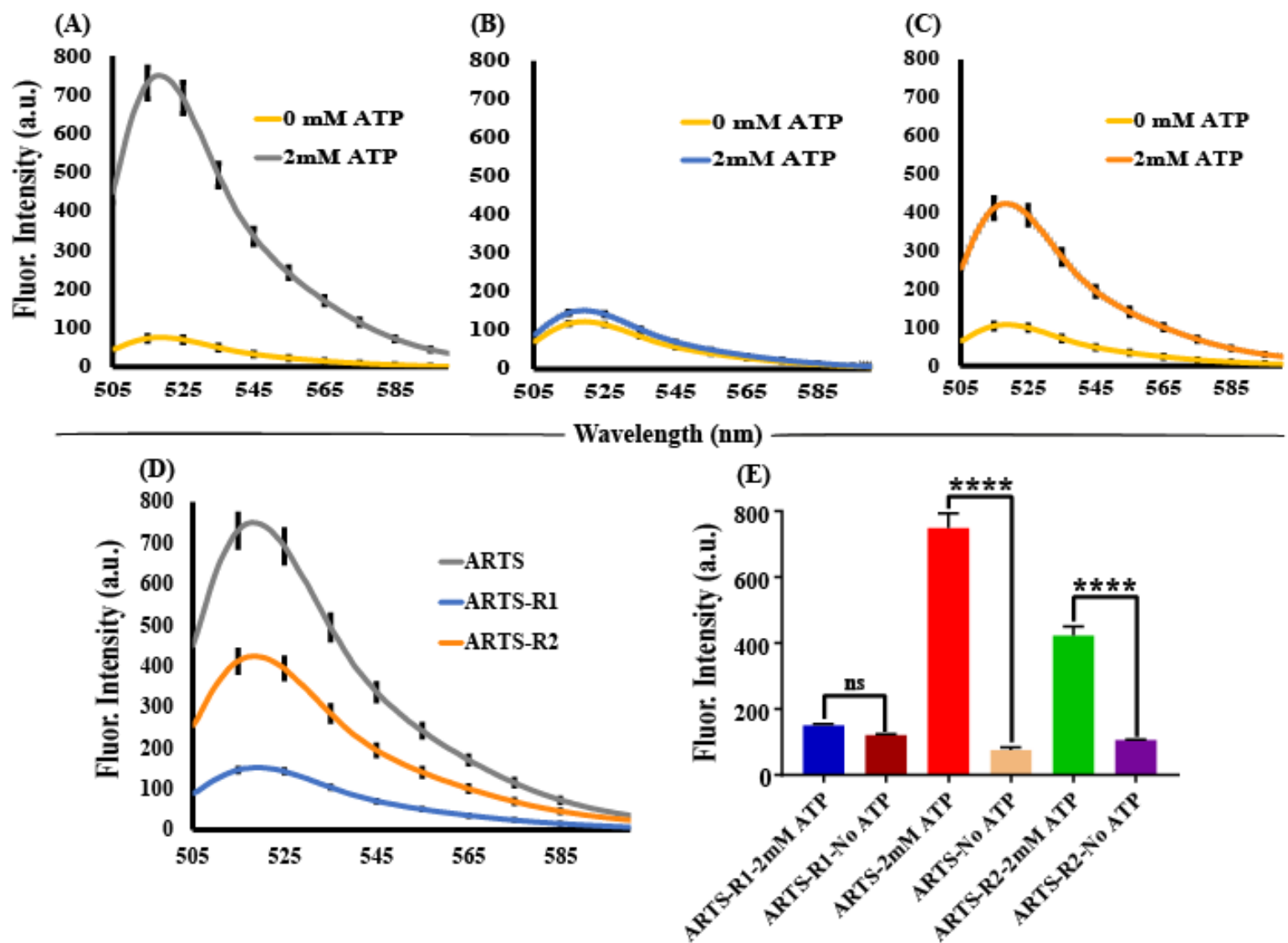

Figure 3: Fluorescence spectra of the FAM fluorophore of ARTS, ARTS-R1 and ARTS-R2 in the absence and presence of ATP. The fluorescence spectrum of (A) 
ARTS, (B) ARTS-R1 and (C) ARTS-R2 in the absence and presence of $2 \mathrm{mM}$ ATP. (D) Direct comparison of spectra for the three aptamer constructs in the presence of $2 \mathrm{mM}$ ATP. (E) Bar graph of fluorescence intensity of the aptamers in the presence and absence of $2 \mathrm{mM}$ ATP, reflecting the outcome of three independent specific binding experiments with and without the addition of ATP, using one-way ANOVA with Student's $t$-test performed on GraphPad Prism ns: $p \leq 0.0001,{ }^{* * * *}: p \leq 0.0001$.

To investigate the nucleotide specificity of ARTS, we tested the conformational change of the ARTS constructs in the presence of different nucleotides. The change of the fluorescence signal was measured in the presence of ATP (blue line in Figure 4A-C), GTP (yellow line in Figure 4A), CTP (yellow line in Figure 4B), and UTP (yellow line in Figure $4 C$ ). We did not observe a significant increase in the fluorescence signal with control nucleotides suggesting the specificity of ARTS towards ATP. The control molecules ARTS-R1 and ARTS-R2 were also tested and showed no significant change in fluorescence intensity after the addition of GTP, CTP, or UTP (Figure S-3 and S-4).
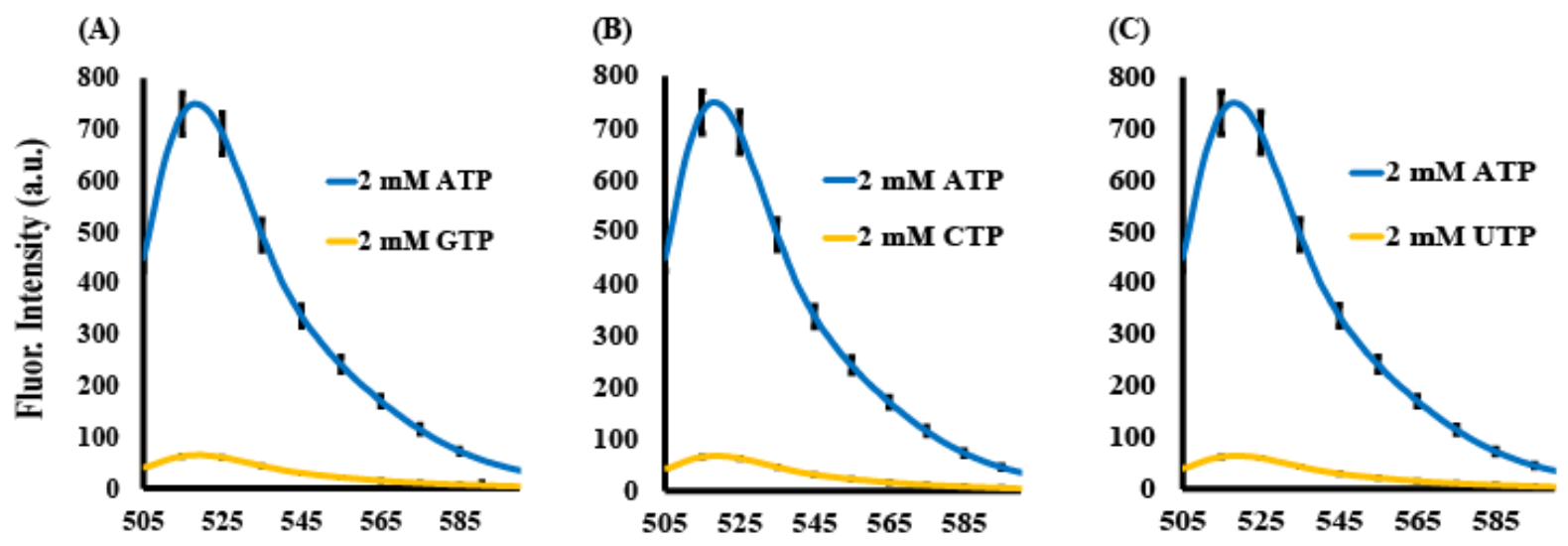

Wavelength (nm)

Figure 4: Analysis of the specificity of the ATP aptamer in ARTS. A) Specificity of ATP aptamer in ARTS with $2 \mathrm{mM}$ ATP and $2 \mathrm{mM}$ GTP, as measured by fluorescence intensity. B) Specificity of the ATP aptamer in ARTS with $2 \mathrm{mM}$ ATP and $2 \mathrm{mM}$ CTP. C) Specificity of ATP aptamer in ARTS with $2 \mathrm{mM}$ ATP and $2 \mathrm{mM}$ UTP. ARTS was prepared by heating at $95^{\circ} \mathrm{C}$ for 5 mins and then cooling down to $25^{\circ} \mathrm{C}$ over a period of 30 minutes. Six samples of 250nM ARTS were prepared in Tris-HCl Buffer $(10 \mathrm{mM}$, 
$\mathrm{pH}=8.4$ ) and $6 \mathrm{mM} \mathrm{MgCl}_{2}$. To each sample was added ATP, GTP, CTP or UTP at a final concentration of $2 \mathrm{mM}$.

\section{Specific Binding to Jurkat E6.1 Cells:}

We next evaluated the specific recognition of T-cell leukemia known to express high levels of TCR-CD3 $\varepsilon$. ARTS is a bifunctional sensor, first detecting the presence of an altered biochemical composition in the TME, followed by the presence of tumor cells. To test anti-CD3 $\varepsilon$ binding, 100nM of ARTS, or its controls, were combined in solution with $500 \mu \mathrm{M}$ ATP, followed by incubation for 1 hour with $1 \times 10^{5}$ Jurkat E6. 1 cells. While ARTS specifically recognized Jurkat. E6 cells in the presence of ATP, no specific cell binding was observed for ARTS-R1 and ARTS-R2, suggesting the ability of ARTS to detect Jurkat.E6 cells specifically (Figure 5A-E). The affinity of the anti-TCR-CD3 aptamer segment in ARTS towards TCR-CD3 $\varepsilon$ was evaluated using a range of ARTS concentrations against a fixed ATP concentration. The affinity was calculated as 135 $\mathrm{nM}$ indicating that the bispecific design does not significantly alter TCR-CD3 $\varepsilon$ aptamer's affinity in the bispecific design (Figure 5F). We then tested the binding affinity of ARTS against Jurkat E6.1 cells using a fixed ARTS concentration of 100nM with varying concentrations of ATP (Figure 5G) to evaluate whether the bispecific design had altered the affinity of the ATP aptamer towards ATP. We observed no significant change to the ATP aptamer's affinity to ATP $(\mathrm{Kd}=334.2 \mu \mathrm{M})$, suggesting again, that the functional fold of the ATP binding aptamer segment in the bispecific design is uninterrupted.

The specificity of the anti-CD3 $\varepsilon$ aptamer in ARTS was further evaluated using TCRCD3 negative cell lines (Figures S-5 and S-6). We used ARTS and ARTS-R1 in the presence of $500 \mu \mathrm{M}$ ATP with Jurkat E6.1 cells (Figure S-5A), Ramos cells (Figure S$5 B$ ), and CA46 cells (Figure S-5C). The overall binding ratio between ARTS and ARTS-R1 using TCR-CD3 positive and negative cell lines (Figure S-5D) shows that ARTS specifically detects only TCR-CD3e positive Jurkat E6.1 cells in response to ATP concentration. The analysis of binding of ARTS and ARTS-R2 to Jurkat E6.1 cells in the absence and presence of $500 \mu \mathrm{M}$ ATP (Figure S-6A) using control Ramos cells (Figure S-6B), and CA 46 cells (Figure S-5C and S-6D) confirms the specificity of ARTS towards Jurkat E6.1 cells mediated by the conformational switch induced by ATP. Collectively, the observed high specificity of ARTS against CD $3 \varepsilon$-expressing 
Jurkat E6.1 cells, suggests the specificity, robustness, and general applicability of this bispecific design in tumor detection.

(A)

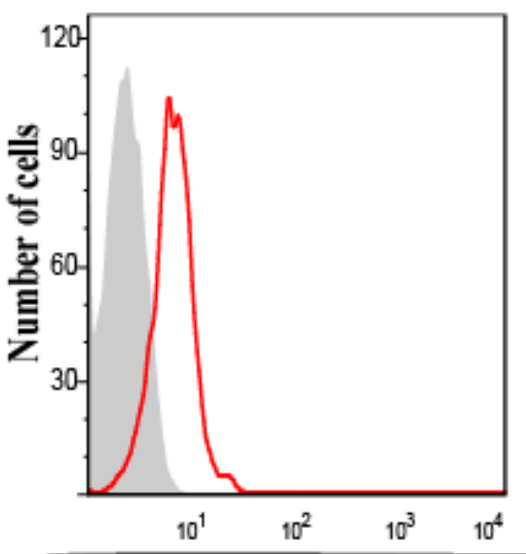

(B)

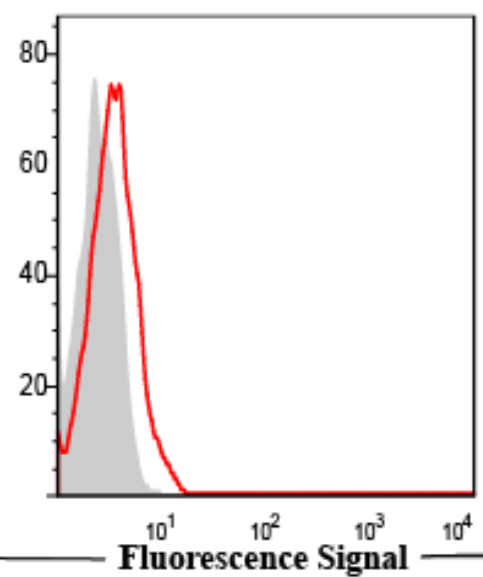

(C)

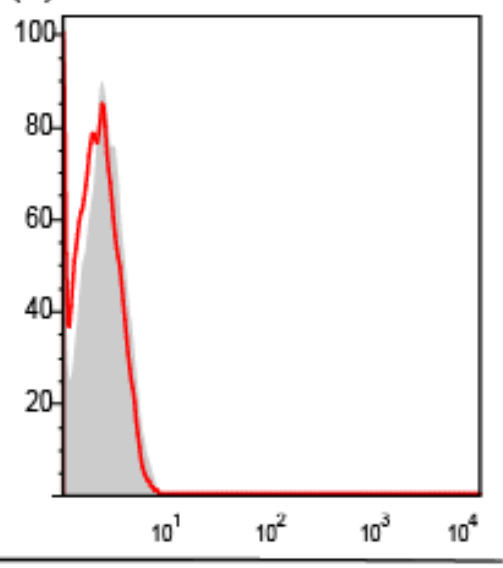

- ARTS With ATP

-ARTS-R1 With ATP

-ARTS-R2 With ATP ARTS Without ATP

-ARTS-R1 Without ATP

(D) Binding Ratio (ARTS vs. ARTS-Rl)

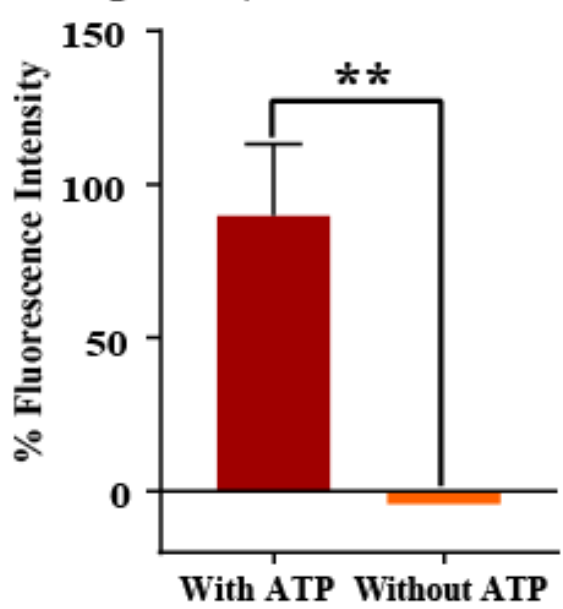

(F)

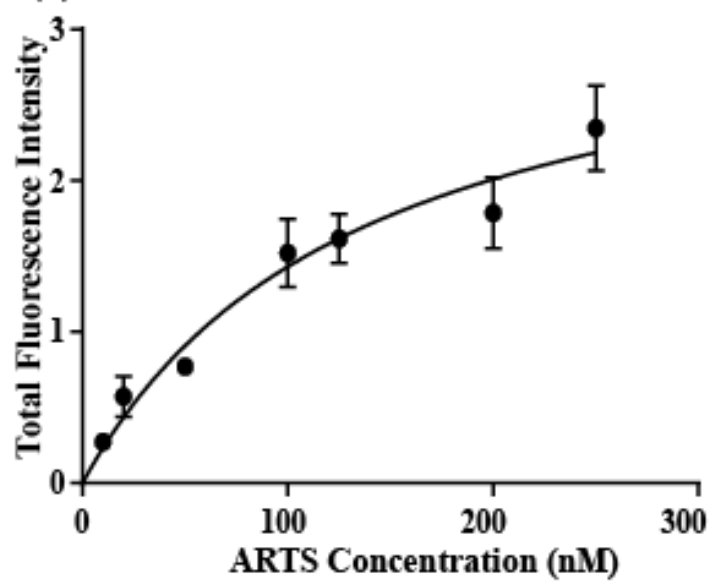

(E) Binding Ratio (ARTS vs. ARTS-R2)

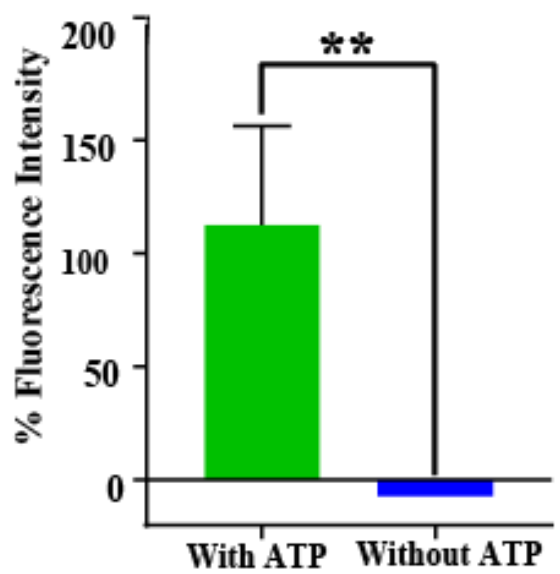

(G)

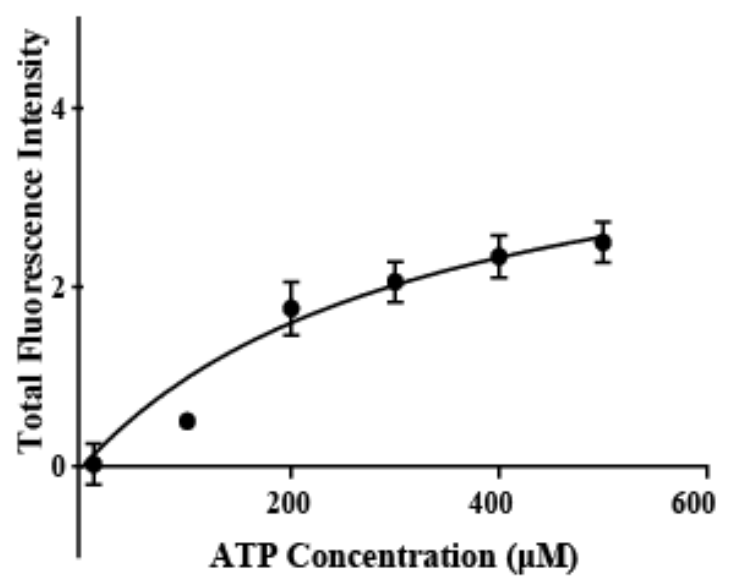

Figure 5: Analysis of specificity and affinity of ARTS, ARTS-R1 and ARTS-R2 against TCR-CD3 $\varepsilon$ expressed on Jurkat E6.1 cells. A) Flow cytometry binding assay of ARTS 
targeting Jurkat E6.1 cells in the presence of ATP (Red) and in the absence of ATP (Grey). B) Flow cytometry binding assay of ARTS-R1 targeting Jurkat E6.1 cells in the presence of ATP (Red) and in the absence of ATP (Grey). (C) Flow cytometry binding assay of ARTS-R2 in the presence of ATP (Red) and in the absence of ATP (Grey). All were folded by preincubating with either $500 \mu \mathrm{M}$ ATP or without ATP, followed by incubation with $1 \times 10^{5}$ Jurkat E6.1 cells for 1 hour in CSB. D) Binding ratio of ARTS in the presence and absence of ATP using ARTS-R1's background fluorescence signal. E) Binding ratio of ARTS in the presence and absence of ATP using ARTS-R2's fluorescence background. The results were analyzed using one-way ANOVA with Student's $t$-test performed on GraphPad Prism ${ }^{* *}: p=0.0021,{ }^{* *}: p=0.0009$. F) Affinity curve of ARTS against Jurkat E6.1 cells as a function of ARTS concentration (10, 20, 50, 100, 125, 200, and $250 \mathrm{nM}$ ). G) Affinity curve of ARTS against Jurkat E6.1 cells plotted as a function of ATP concentration (10, 100, 200, 300, 400 and 500 $\mu \mathrm{M})$.

\section{Conclusion}

DNA-based systems, specifically aptamers, serve as a promising molecular tool owing to their low cost and easily modifiable synthetic analogs with favorable pharmacokinetic properties to design modular DNA architectures. ${ }^{23-26}$ Bispecific designs of aptamers has been evalutated for thereapeutic development before. ${ }^{27,} 28$ However, to our knowledge, there are no bispecific aptamers desgins have been explored for sensing and detection. We herein demonstrated a DNA aptamer-based bispecific system to enhance the specificity of tumor cell detection by utilizing the unique biochemical composition of the TME. This dual-specific design exploited both the dynamic nature of DNA self-assembly and the specific recognition ability of aptamers toward small molecules and proteins. By combining these features, we introduced a de novo, in situ aptamer-based sensor as a superior platform for sensing tumor cells with added specificity to the biochemical features of the TME. We showed that ARTS could be activated in the presence of a high concentration of ATP and that T-cell binding was only promoted under these conditions. Thus, our prototype design introduces a novel concept of sensor design while expanding aptamer versatility in the design of sensors and smart diagnostic platforms. 


\section{Materials and Methods:}

\section{Cell cultures and reagents:}

Jurkat, Clone E6.1 (T lymphocyte), cells were purchased from the American Type Culture Collection (ATCC). The cell line was cultured in HyClone RPMI-1640 (+25mM HEPES, +L-Glutamine) medium supplemented with 100 units $/ \mathrm{mL}$ penicillinstreptomycin 1\% (Corning), 1\% MEM Non-Essential Amino Acids (Gibco) and 10\% fetal bovine serum (Heat Inactivated, Gibco). All cell lines were routinely evaluated on a Flow Cytometer (FACScan, Becton Dickinson) for the expression of CD marker using anti-hCD3E (PE-conjugated Mouse IgG1, R\&D Systems) antibody to authenticate the cell line. All conformational assays were tested using Adenosine-5'triphosphate, ATP, from a stock solution of $100 \mathrm{mM}$ (ThermoFisher). The specificity assay was performed using $2 \mathrm{mM}$ of Adenosine-5'-triphosphate, ATP, Uridine-5'triphosphate, UTP, Cytidine-5'-triphosphate, CTP, and Guanosine-5'-triphosphate, GTP, from a stock solution of 100mM (ThermoFisher). All aptamer solutions were prepared in $10 \mathrm{mM}$ Tris- $\mathrm{HCl}$ (Thermo Scientific) adjusted to $\mathrm{pH}=8.4$, with $6 \mathrm{mM} \mathrm{MgCl}_{2}$ (Sigma Aldrich) from a stock solution of $1 \mathrm{M}$ Tris- $\mathrm{HCl}$ (ThermoFisher). All DNA sequences were ordered HPLC-purified from Integrated DNA Technologies (IDT) and dual-modified with 6-Carboxyfluorescein (6-FAM) and lowa Black Fluorescence Quencher (IBFQ) at the 5' and 3', respectively.

\section{Preparation of Solutions:}

All bispecific molecules: ARTS, ARTS-R1 and ARTS-R2, were reconstituted in $10 \mathrm{mM}$ Tris- $\mathrm{HCl}, \mathrm{pH}=8.4$, to make a $100 \mu \mathrm{M}$ stock solution, gently shaking for 3 hours and then refrigerated overnight to dissolve. Afterwards, the accurate concentrations of each aptamer were determined using a UV-Vis spectrophotometer (Thermo Scientific) at $260 \mathrm{~nm}$ wavelength. A sub-stock solution of $10 \mu \mathrm{M}$ was prepared for all aptamer molecules by dilution of each of the respective stock solutions with $10 \mathrm{mM}$ Tris- $\mathrm{HCl}$, $\mathrm{pH}=8.4$, and $6 \mathrm{mM} \mathrm{MgCl}_{2}$ buffer to prepare the various working solutions.

\section{Cell Binding Buffers:}

All binding assays were performed using a Cell Suspension Buffer (CSB) composed of HyClone RPMI-1640 (+25mM HEPES +L-Glutamine) medium containing 200 mg/L tRNA (Sigma-Aldrich), 2 g/L Bovine Serum Albumin (BSA, Fisher Scientific) and 200 $\mathrm{mg} / \mathrm{L}$ Salmon Sperm DNA solution (Invitrogen). 


\section{Aptamer Folding Conditions:}

Prior to mixing with cells for binding assay, the aptamers were prepared in $10 \mathrm{mM}$ Tris$\mathrm{HCl}, \mathrm{pH}=8.4$, and $6 \mathrm{mM} \mathrm{MgCl}_{2}$ buffer placed in $95^{\circ} \mathrm{C}$ for 5 mins to denature undesired secondary structures, followed by cooling down to $25^{\circ} \mathrm{C}$ in a $5 \% \mathrm{CO} 2$ incubator for 30 minutes to fold into the most stable secondary structure in the presence of ATP.

\section{Thermal stability of the aptamer:}

To check thermal stability, $250 \mathrm{nM}$ of each molecule (in $500 \mu \mathrm{L} 10 \mathrm{mM}$, Tris-HCl, $\mathrm{pH}=$ 8.4 , and $6 \mathrm{mM} \mathrm{MgCl}_{2}$ ) were placed in a Supermicro quartz cuvette for fluorescence measurements using the Cary Eclipse fluorescence spectrophotometer with a Cary temperature controller (Agilent). The emission wavelength used in the thermal stability assays was the emission wavelength of the 6-FAM fluorophore, $\lambda_{\mathrm{em}}=520 \mathrm{~nm}$, and the excitation wavelength was $\lambda e x=495$ at different time points (each 5 mins) with temperature changes from $10^{\circ} \mathrm{C}$ to $90^{\circ} \mathrm{C}$.

\section{Investigation of aptamer conformation:}

All molecules (ARTS, ART-R1 and ARTS-R2) were prepared in a final volume of 500 $\mu \mathrm{L} 10 \mathrm{mM}$ Tris- $\mathrm{HCl}, \mathrm{pH}=8.4$, with $6 \mathrm{mM} \mathrm{MgCl}_{2}$, to make a final concentration of 250 $\mathrm{nM}$. All molecules were folded, as described above, transferred to a Supermicro quartz cuvette, and then placed in the Cary Eclipse fluorescence spectrophotometer at 25 ${ }^{\circ} \mathrm{C}$. The fluorescence intensity of ARTS was measured at different concentrations of ATP in the range of 0-4 $\mathrm{mM}$. The solutions were mixed well prior to fluorescence measurements. The excitation wavelength of the 6-FAM fluorophore was $\lambda_{\mathrm{ex}}=495$ $\mathrm{nm}$, and emission was scanned between $\lambda_{\mathrm{em}}=505$ and $600 \mathrm{~nm}$. The emission slit was $5 \mathrm{~nm}$, whereas the excitation slit was $10 \mathrm{~nm}$. The fluorescence intensity of each molecule was measured in the absence of ATP and then in the presence of ATP at final concentrations of 0.5-4 mM. The mean of three separate measurements of $0 \mathrm{mM}$ ATP and $2 \mathrm{mM}$ ATP concentration was plotted to study the ATP-dependent fluorescence.

\section{Specificity of ARTS towards ATP over GTP, UTP and CTP:}


Prior to starting the specificity assay, $250 \mathrm{nM}$ of each construct in $500 \mu \mathrm{L}$ Tris- $\mathrm{HCl}(10$ $\mathrm{mM}, \mathrm{pH}=8.4,6 \mathrm{mM} \mathrm{MgCl}$ ) was folded and mixed with $2 \mathrm{mM}$ of each nucleotide (ATP, UTP, GTP and CTP). The solutions were transferred to a quartz cuvette and placed in a fluorescence spectrophotometer at $25^{\circ} \mathrm{C}$. The excitation wavelength of the 6-FAM fluorophore was $\lambda_{\mathrm{ex}}=495 \mathrm{~nm}$, and the emission was scanned between $\lambda_{\mathrm{em}}=505$ and $600 \mathrm{~nm}$. The emission slit was $5 \mathrm{~nm}$, whereas the excitation slit was $10 \mathrm{~nm}$.

\section{Cell binding assays:}

Jurkat E6.1 cells were prepared by washing three times with $3 \mathrm{~mL}$ HyClone RPMI1640 (+25mM HEPES +L-Glutamine) medium prior to aptamer binding. All sequences were prepared at an initial concentration of $200 \mathrm{nM}$ from $1 \mu \mathrm{M}$ sub-stock solutions in $10 \mathrm{mM}$ Tris- $\mathrm{HCl}, \mathrm{pH}=8.4$, and $6 \mathrm{mM} \mathrm{MgCl}_{2}$. Prior to mixing aptamers with the cells, $200 \mathrm{nM}$ of ATRS or control molecules in Tris- $\mathrm{HCl}\left(10 \mathrm{mM}, \mathrm{pH}=8.4,6 \mathrm{mM} \mathrm{MgCl}_{2}\right)$ were folded at $95{ }^{\circ} \mathrm{C}$ for 5 minutes and then transferred to $25{ }^{\circ} \mathrm{C}$ for 30 minutes.

After folding, $75 \mu \mathrm{L}$ of ARTS with and without ATP were mixed with $75 \mu \mathrm{L}$ of $1 \times 10^{5}$ Jurkat E 6.1 in CSB to give a final concentration of $100 \mathrm{nM}$ for the aptamer molecule and $500 \mu \mathrm{M}$ for ATP in a total volume of $150 \mu \mathrm{L}$. A equal volume of buffer was added to the sample that served as a control without ATP. Binding of each aptamer was analyzed using flow cytometry by counting 5000 events. As a positive control, Jurkat

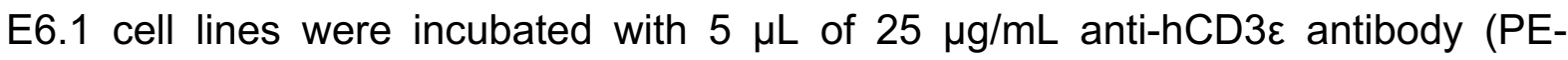
conjugated Mouse IgG1, R\&D Systems) or $2 \mu \mathrm{L}$ of $200 \mu \mathrm{g} / \mathrm{mL}$ isotype control (PE Mouse lgG1, $\mathrm{K}$, BD Biosciences) for 30 minutes on ice, followed by a wash with $2 \mathrm{~mL}$ of RPMI-1640 medium and reconstitution in $250 \mu \mathrm{L}$ RPMI-1640 medium. Binding events were monitored in FL1 Green (515-545 nm) for the aptamer and in FL2 Yellow (565-605 nm; 564-606 nm) for the antibody, counting 5000 events using flow cytometry. 


\section{Specificity assay with different cell lines:}

Jurkat E6.1, Ramos, and CA46 cells were prepared by washing three times with $3 \mathrm{~mL}$ HyClone RPMI-1640 (+25mM HEPES, +L-Glutamine) medium prior to aptamer binding to the cells. All sequences were prepared at an initial concentration of $200 \mathrm{nM}$ from $1 \mu \mathrm{M}$ sub-stock solutions in $10 \mathrm{mM}$ Tris- $\mathrm{HCl}, \mathrm{pH}=8.4$, and $6 \mathrm{mM} \mathrm{MgCl}_{2}$. Aptamers and cells were first mixed; then $200 \mathrm{nM}$ of each construct in Tris- $\mathrm{HCl}(10 \mathrm{mM}, \mathrm{pH}=8.4$, $6 \mathrm{mM} \mathrm{MgCl} 2$ ) were folded at $95^{\circ} \mathrm{C}$ for 5 minutes and then transferred to $25^{\circ} \mathrm{C}$ for 30 minutes.

After folding, $75 \mu \mathrm{L}$ of each construct sample were mixed with $75 \mu \mathrm{L}$ containing $1 \times 10^{5}$ of each cell line in CSB to give a final concentration of $100 \mathrm{nM}$ for the ARTS constructs and $500 \mu \mathrm{M}$ for ATP $(5 \mu \mathrm{L}$ from stock solution of $100 \mathrm{mM}$ ) in a total volume of $150 \mu \mathrm{L}$. An equal volume of buffer was added to the sample that served as a control without ATP. Binding of each aptamer was analyzed using flow cytometry by counting 5000 events. As a positive control, Jurkat E6.1 cells were incubated with $5 \mu \mathrm{L}$ of $25 \mu \mathrm{g} / \mathrm{mL}$ anti-hCD3 $\varepsilon$ antibody (PE-conjugated Mouse IgG1, R\&D Systems) or $2 \mu \mathrm{L}$ of 200 $\mu \mathrm{g} / \mathrm{mL}$ isotype control (PE Mouse IgG1, $\mathrm{k}, \mathrm{BD}$ Biosciences) for 30 minutes on ice, followed by a one-time wash with $2 \mathrm{~mL}$ of RPMl-1640 medium and reconstitution in $250 \mu \mathrm{L}$ RPMI-1640 medium. As a negative control, Ramos and CA46 cell lines were

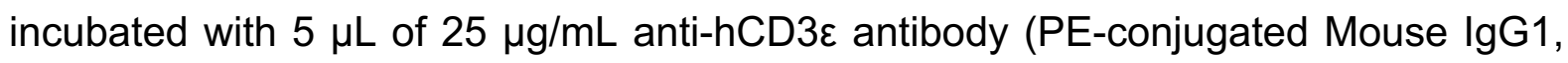
R\&D Systems) or $2 \mu \mathrm{L}$ of $200 \mu \mathrm{g} / \mathrm{mL}$ isotype control (PE Mouse IgG1, K, BD Biosciences) for 30 minutes on ice, followed by a one-time wash with $2 \mathrm{~mL}$ of RPMI1640 medium and reconstitution in $250 \mu \mathrm{L}$ RPMI-1640 medium. Binding events were monitored in FL1 Green (515-545 nm) for the aptamer and in FL2 Yellow (565-605 $\mathrm{nm} ; 564-606 \mathrm{~nm}$ ) for the antibody, counting 5000 events using flow cytometry. 


\section{References:}

1. Reina-Campos, M.; Moscat, J.; Diaz-Meco, M., Metabolism shapes the tumor microenvironment. Curr Opin Cell Biol 2017, 48, 47-53.

2. Hsu, P. P.; Sabatini, D. M., Cancer cell metabolism: Warburg and beyond. Cell 2008, 134 (5), 703-7.

3. Palm, W.; Thompson, C. B., Nutrient acquisition strategies of mammalian cells. Nature 2017, 546 (7657), 234-242.

4. Quail, D. F.; Joyce, J. A., Microenvironmental regulation of tumor progression and metastasis. Nat Med 2013, 19 (11), 1423-37.

5. Pavlova, N. N.; Thompson, C. B., The Emerging Hallmarks of Cancer Metabolism. Cell Metab 2016, 23 (1), 27-47.

6. Joyce, J. A.; Fearon, D. T., T cell exclusion, immune privilege, and the tumor microenvironment. Science 2015, 348 (6230), 74-80.

7. Vijayan, D.; Young, A.; Teng, M. W. L.; Smyth, M. J., Targeting immunosuppressive adenosine in cancer. Nat Rev Cancer 2017, 17 (12), 765.

8. Hu, Q.; Huang, Z.; Duan, Y.; Fu, Z.; Bin, L., Reprogramming Tumor Microenvironment with Photothermal Therapy. Bioconjug Chem 2020, 31 (5), 1268-1278.

9. Dong, Y.; Dong, S.; Wang, Z.; Feng, L.; Sun, Q.; Chen, G.; He, F.; Liu, S.; Li, W.; Yang, P., Multimode Imaging-Guided Photothermal/Chemodynamic Synergistic Therapy Nanoagent with a Tumor Microenvironment Responded Effect. ACS Appl Mater Interfaces 2020, 12 (47), 52479-52491.

10. Gillies, R. J.; Raghunand, N.; Karczmar, G. S.; Bhujwalla, Z. M., MRI of the tumor microenvironment. J Magn Reson Imaging 2002, 16 (4), 430-50.

11. Joyce, J. A.; Pollard, J. W., Microenvironmental regulation of metastasis. Nat Rev Cancer 2009, 9 (4), 239-52.

12. Scharping, N. E.; Delgoffe, G. M., Tumor Microenvironment Metabolism: A New Checkpoint for Anti-Tumor Immunity. Vaccines (Basel) 2016, 4 (4).

13. Di Virgilio, F.; Sarti, A. C.; Falzoni, S.; De Marchi, E.; Adinolfi, E., Extracellular ATP and P2 purinergic signalling in the tumour microenvironment. Nat Rev Cancer 2018, 18 (10), 601-618.

14. Koudrina, A.; DeRosa, M. C., Advances in Medical Imaging: Aptamer- and PeptideTargeted MRI and CT Contrast Agents. ACS Omega 2020, 5 (36), 22691-22701.

15. Kufer, P.; Lutterbuse, R.; Baeuerle, P. A., A revival of bispecific antibodies. Trends Biotechnol 2004, 22 (5), 238-44.

16. Byrne, H.; Conroy, P. J.; Whisstock, J. C.; O'Kennedy, R. J., A tale of two specificities: bispecific antibodies for therapeutic and diagnostic applications. Trends Biotechnol 2013, 31 (11), 621-32.

17. Hernandez-Lopez, R. A.; Yu, W.; Cabral, K. A.; Creasey, O. A.; Lopez Pazmino, M. D. P.; Tonai, Y.; De Guzman, A.; Makela, A.; Saksela, K.; Gartner, Z. J.; Lim, W. A., T cell circuits that sense antigen density with an ultrasensitive threshold. Science 2021, 371 (6534), 1166-1171. 
18. Cui, F.; Yue, Y.; Zhang, Y.; Zhang, Z.; Zhou, H. S., Advancing Biosensors with Machine Learning. ACS Sens 2020, 5 (11), 3346-3364.

19. Lim, C. Z. J.; Zhang, L.; Zhang, Y.; Sundah, N. R.; Shao, H., New Sensors for Extracellular Vesicles: Insights on Constituent and Associated Biomarkers. ACS Sens 2020, 5 (1), 4-12.

20. Di, Z.; Zhao, J.; Chu, H.; Xue, W.; Zhao, Y.; Li, L., An Acidic-MicroenvironmentDriven DNA Nanomachine Enables Specific ATP Imaging in the Extracellular Milieu of Tumor. Adv Mater 2019, 31 (33), e1901885.

21. Huizenga, D. E.; Szostak, J. W., A DNA aptamer that binds adenosine and ATP. Biochemistry 1995, 34 (2), 656-65.

22. Zumrut, H. E.; Batool, S.; Argyropoulos, K. V.; Williams, N.; Azad, R.; Mallikaratchy, P. R., Integrating Ligand-Receptor Interactions and In Vitro Evolution for Streamlined Discovery of Artificial Nucleic Acid Ligands. Mol Ther Nucleic Acids 2019, 17, 150-163.

23. Freage, L.; Boykoff, N.; Mallikaratchy, P., Utility of Multivalent Aptamers to Develop Nanoscale DNA Devices against Surface Receptors. ACS Omega 2021, 6 (19), 12382-12391.

24. Freage, L.; Jamal, D.; Williams, N. B.; Mallikaratchy, P. R., A Homodimeric Aptamer Variant Generated from Ligand-Guided Selection Activates the T Cell Receptor Cluster of Differentiation 3 Complex. Mol Ther Nucleic Acids 2020, 22, 167-178.

25. Keller, A.; Linko, V., Challenges and Perspectives of DNA Nanostructures in Biomedicine. Angew Chem Int Ed Engl 2020, 59 (37), 15818-15833.

26. Nummelin, S.; Shen, B.; Piskunen, P.; Liu, Q.; Kostiainen, M. A.; Linko, V., Robotic DNA Nanostructures. ACS Synth Biol 2020, 9 (8), 1923-1940.

27. Tang, Z.; Mallikaratchy, P.; Yang, R.; Kim, Y.; Zhu, Z.; Wang, H.; Tan, W., Aptamer switch probe based on intramolecular displacement. J Am Chem Soc 2008, 130 (34), 11268-9. 28. Boltz, A.; Piater, B.; Toleikis, L.; Guenther, R.; Kolmar, H.; Hock, B., Bi-specific aptamers mediating tumor cell lysis. J Biol Chem 2011, 286 (24), 21896-905. 


\section{A bispecific aptamer sensor towards T-cell leukemia detection in the tumor microenvironment}

Natalie Boykoff ${ }^{2}$, Lina Freage ${ }^{1}$, Jared Lenn ${ }^{4}$, and Prabodhika Mallikaratchy ${ }^{1,2,3^{*}}$.

${ }^{1}$ Department of Chemistry, Lehman College, The City University of New York, 250 Bedford Park Blvd., West, Bronx, NY 10468, USA

2 Ph.D. Programs in Chemistry and Biochemistry, CUNY Graduate Center, 365 Fifth Avenue, New York, NY 10016, USA

${ }^{3}$ Ph.D. Program in Molecular, Cellular and Developmental Biology, CUNY Graduate Center, 365 Fifth Avenue, New York, NY 10016, USA

${ }^{4}$ The Bronx High School of Science, 75 W 205 ${ }^{\text {th }}$ Street, Bronx, NY 10468

*To whom correspondence should be addressed: Prabodhika Mallikaratchy, Department of Chemistry, Lehman College, The City University of New York, 250 Bedford Park West, Bronx New York, NY 10468;

prabodhika.mallikaratchy@lehman.cuny.edu; Phone: 347-577-4082. 

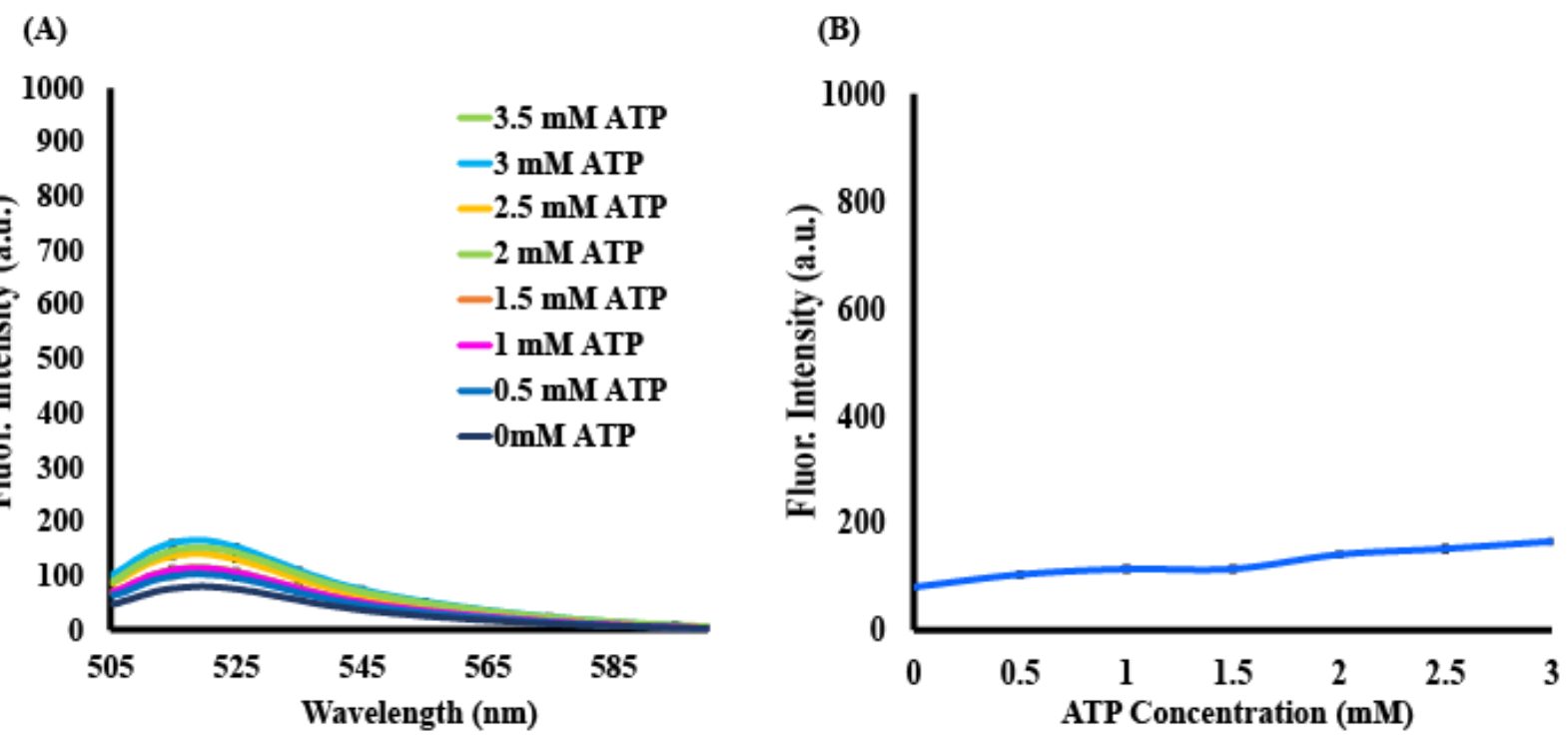

Figure S-1: Titration assay of ARTS-R1 using different concentrations of ATP. A) Fluorescence spectrum of ARTS-R1 in the absence and presence of $0.5,1,1.5,2,2.5$, $3,3.5$, and $4 \mathrm{mM}$ ATP. B) The calibration plot of ARTS-R1 over the range of $0.5,1,1.5$, $2,2.5,3,3.5$, and $4 \mathrm{mM}$ ATP. The titration assay was done using $250 \mathrm{nM}$ ARTS-R1 prepared in $500 \mu \mathrm{L}$ of $10 \mathrm{mM}$ Tris- $\mathrm{HCl}$ with $6 \mathrm{mM} \mathrm{MgCl} 2, \mathrm{pH}=8.4$. TheARTS-R1 was folded by heating at $95^{\circ} \mathrm{C}$ for 5 mins to denature undesirable secondary structures and then cooling to $25^{\circ} \mathrm{C}$ for 30 mins. Following this, the construct was transferred to a quartz cuvette and placed in the Cary Eclipse fluorescence spectrophotometer so the fluorescence intensity without ATP, and with $0.5,1,1.5,2,2.5,3,3.5$, and $4 \mathrm{mM}$ ATP (final concentrations) could be measured. The fluorescence spectra were measured using an excitation wavelength of the 6-FAM fluorophore $\lambda e x=495 \mathrm{~nm}$, and thus emission was scanned between $\lambda \mathrm{em}=505-600 \mathrm{~nm}$. The fluorescence spectrum of the dimer was measured at a slit width of $5 \mathrm{~nm}$ for emission and $10 \mathrm{~nm}$ for excitation. ARTS-R1, with randomized ATP aptamer segment, shows no significant increase in fluorescence intensity of the ARTS-R1 as a function of ATP. 

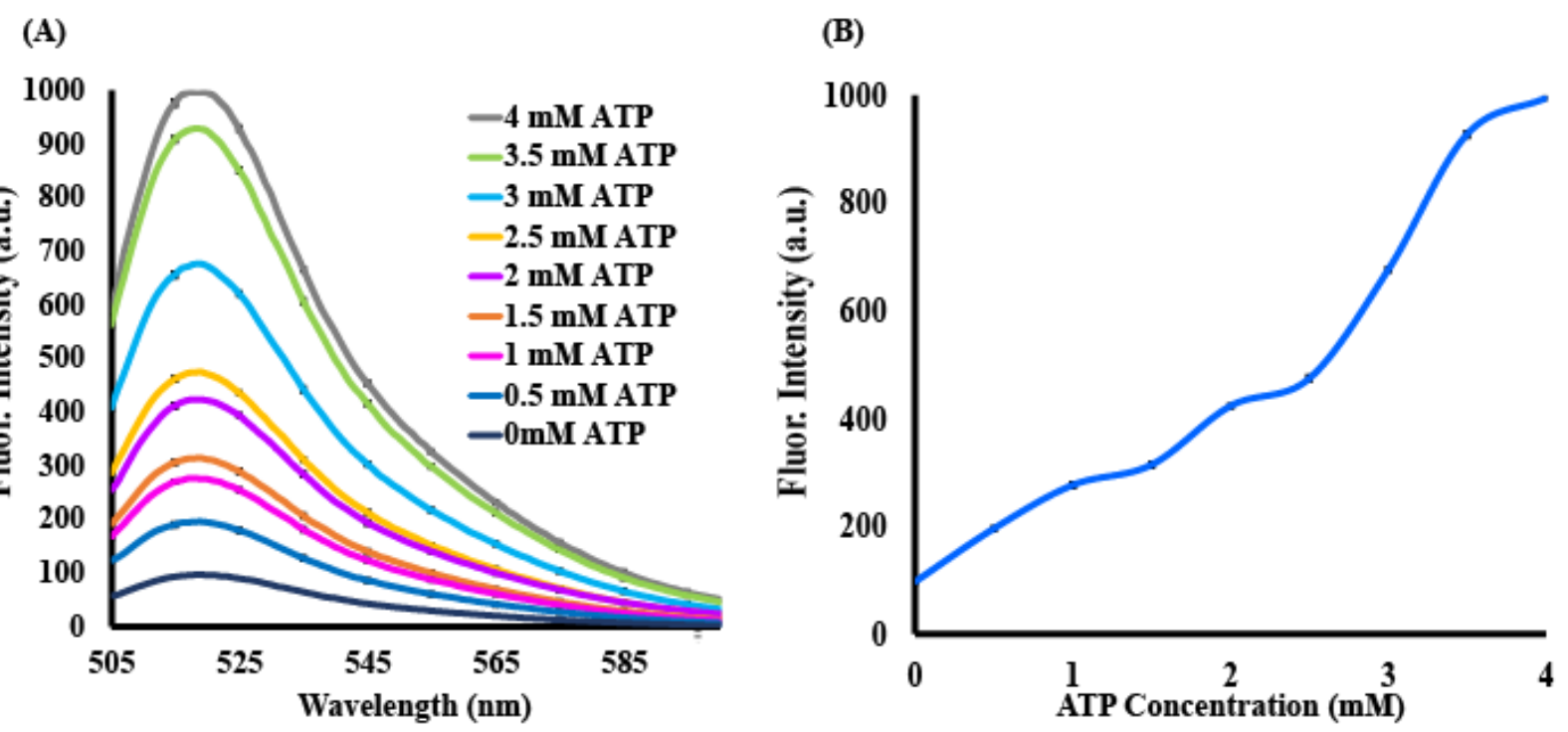

Figure S-2: Titration assay of ARTS-R2 using different concentrations of ATP. A) Fluorescence spectrum of ARTS-R2 in the absence and presence of $0.5,1,1.5,2,2.5$, $3,3.5$ and $4 \mathrm{mM}$ ATP. B) The calibration plot of ARTS-R2 over the range of $0.5,1,1.5$, 2, 2.5, 3, 3.5 and $4 \mathrm{mM}$ ATP. The titration assay was done using $250 \mathrm{nM}$ of ARTS- R2 prepared in $500 \mu \mathrm{L}$ of $10 \mathrm{mM}$ Tris- $\mathrm{HCl}$ with $6 \mathrm{mM} \mathrm{MgCl} 2, \mathrm{pH}=8.4$. The ARTS-R2 was folded by heating at $95^{\circ} \mathrm{C}$ for 5 mins to denature undesirable secondary structures and then cooling to $25^{\circ} \mathrm{C}$ for 30 mins. Following this, the construct was transferred to a quartz cuvette and placed in the Cary Eclipse fluorescence spectrophotometer so the fluorescence intensity without ATP, and with $0.5,1,1.5,2,2.5,3,3.5$, and $4 \mathrm{mM} \mathrm{ATP}$ (final concentrations) could be measured. The fluorescence spectra were measured using excitation wavelength of the 6-FAM fluorophore $\lambda_{\mathrm{ex}}=495 \mathrm{~nm}$, and thus emission was scanned between $\lambda_{\text {em }}=505-600 \mathrm{~nm}$. As expected, ARTS-R2 with ATP aptamer shows a significant increase in fluorescence intensity with ATP. 


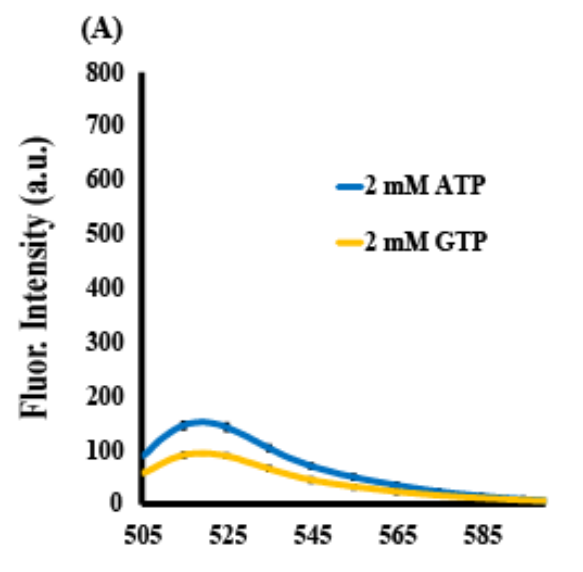

(B)

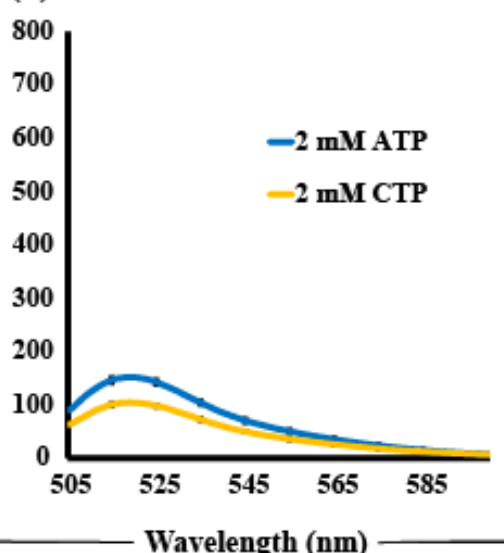

(C)

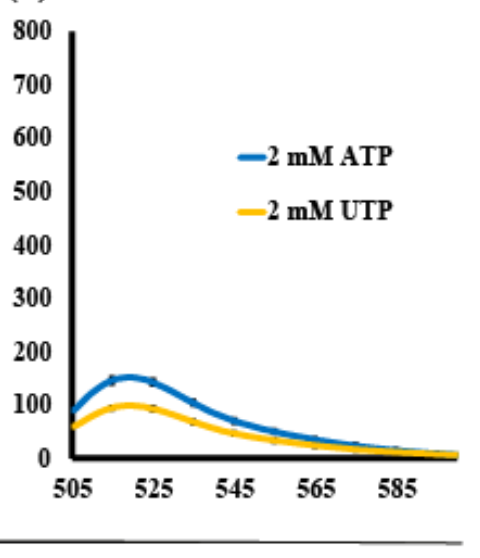

Figure S-3: Analysis of the specificity of the ARTS-R1.

A) Specificity of ARTS-R1 with $2 \mathrm{mM}$ ATP and 2mM CTP. B) Specificity of the ARTS-R1 dimer with $2 \mathrm{mM}$ ATP and $2 \mathrm{mM}$ GTP. C) Specificity of the ARTS-R1 with 2mM ATP and $2 \mathrm{mM}$ UTP. The ARTS-R1 was prepared for the assay by heating at $95^{\circ} \mathrm{C}$ for 5 mins, and then cooling down to $25^{\circ} \mathrm{C}$ over 30 minutes. Four samples of $250 \mathrm{nM}$ ARTSR1 were prepared in a final volume of $500 \mu \mathrm{L}$ in $10 \mathrm{mM}$ Tris- $\mathrm{HCl}$, with $6 \mathrm{mM} \mathrm{MgCl}_{2}, \mathrm{pH}=$ 8.4. Next, $2 \mathrm{mM}$ of each nucleotide (ATP, GTP, CTP and UTP) was added to respective sample. Following this, the construct was transferred to a quartz cuvette and placed in the Cary Eclipse fluorescence spectrophotometer so the fluorescence intensity of $2 \mathrm{mM}$ ATP, GTP, CTP and UTP could be measured. The fluorescence spectra were measured using excitation wavelength of the 6-FAM fluorophore $\lambda_{\text {ex }}=495 \mathrm{~nm}$, and thus emission was scanned between $\lambda_{\mathrm{em}}=505-600 \mathrm{~nm}$. The fluorescence spectrum of each molecule was measured at a slit width of $5 \mathrm{~nm}$ for emission and $10 \mathrm{~nm}$ for excitation. 


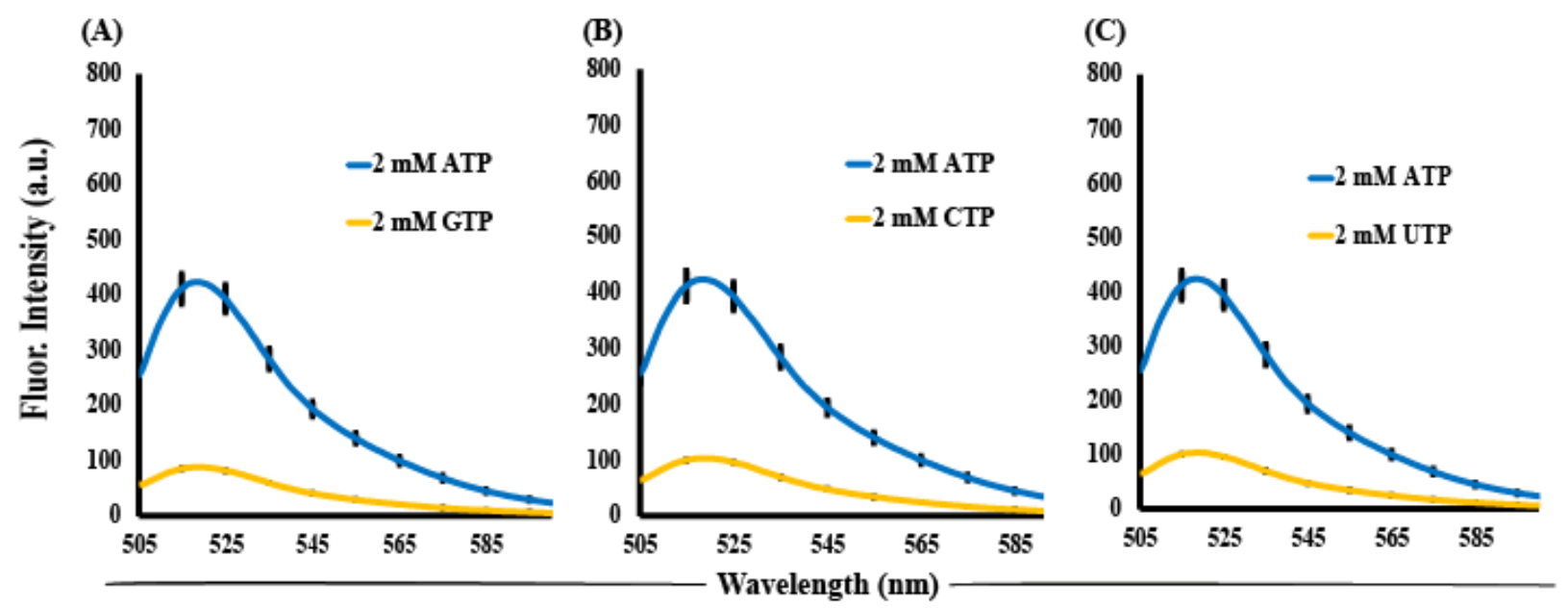

Figure S-4: Analysis of the specificity of the ARTS-R2.

A) Specificity of ARTS-R2 with $2 \mathrm{mM}$ ATP and $2 \mathrm{mM}$ CTP. B) Specificity of the ARTS-R2 with $2 \mathrm{mM}$ ATP and $2 \mathrm{mM}$ GTP. C) Specificity of the ARTS-R2 with $2 \mathrm{mM}$ ATP and $2 \mathrm{mM}$ UTP. The ARTS-R2 was prepared for the assay by heating at $95^{\circ} \mathrm{C}$ for 5 mins, and then cooling down to $25^{\circ} \mathrm{C}$ over 30 minutes. Four samples of $250 \mathrm{nM}$ ARTS-R2 were prepared in a final volume of $500 \mu \mathrm{L}$ in $10 \mathrm{mM}$ Tris- $\mathrm{HCl}$, with $6 \mathrm{mM} \mathrm{MgCl}_{2}, \mathrm{pH}=8.4$. Next, $2 \mathrm{mM}$ of each nucleotide (ATP, GTP, CTP and UTP) was added to respective sample. Following this, the construct was transferred to a quartz cuvette and placed in the Cary Eclipse fluorescence spectrophotometer so the fluorescence intensity of $2 \mathrm{mM}$ ATP, GTP, CTP and UTP could be measured. The fluorescence spectra were measured using excitation wavelength of the 6-FAM fluorophore $\lambda_{\mathrm{ex}}=495 \mathrm{~nm}$, and thus emission was scanned between $\lambda_{\mathrm{em}}=505-600 \mathrm{~nm}$. The fluorescence spectrum of dimer was measured at a slit width of $5 \mathrm{~nm}$ for emission and $10 \mathrm{~nm}$ for excitation. The results show high fluorescence intensity in the presence of ATP nucleotides, and low fluorescence intensity in the presence of GTP, CTP, and UTP nucleotides, demonstrating that the specificity of the ATP aptamer in ARTS-R2. 

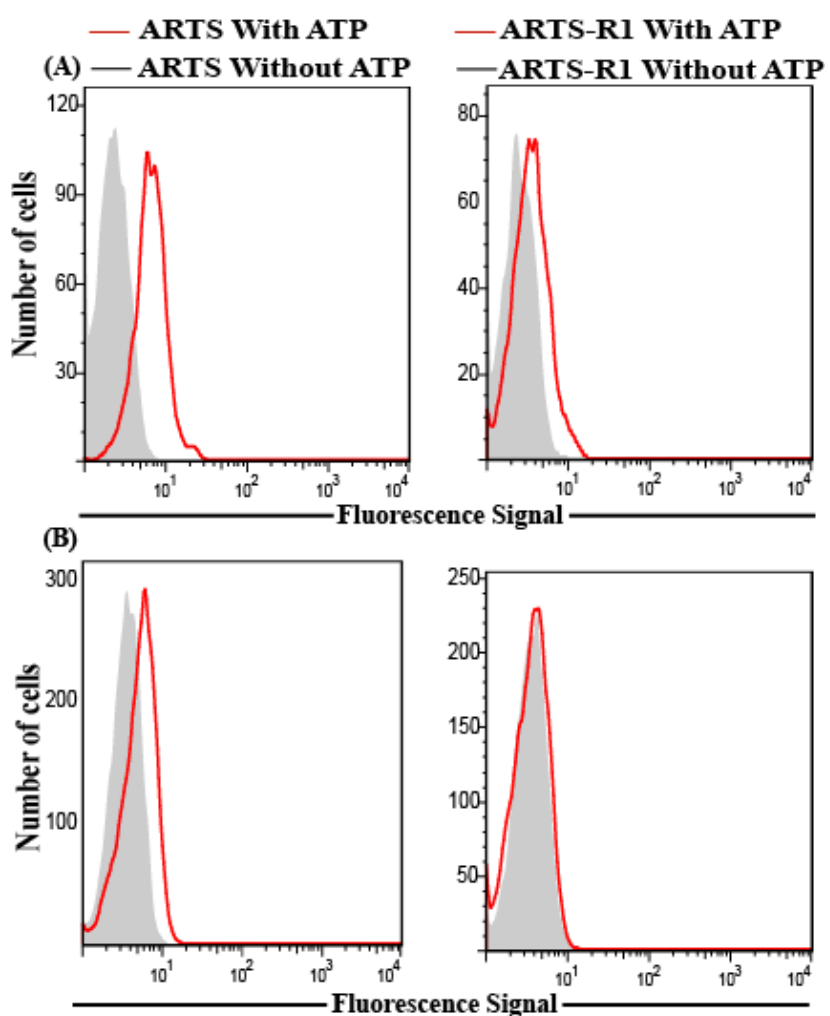

(C)

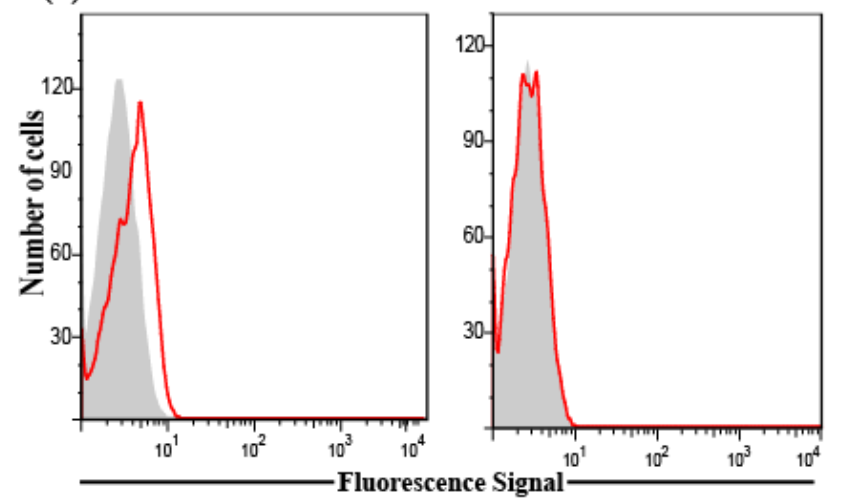

(D)

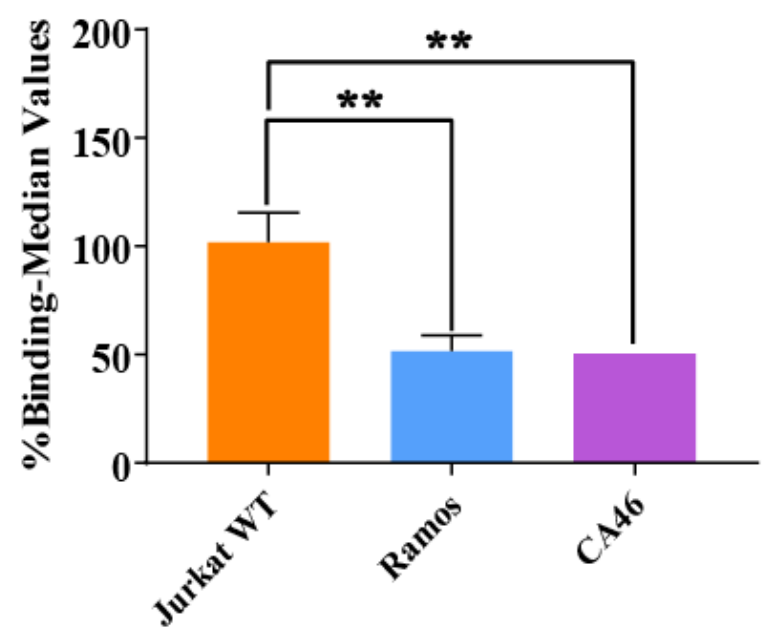


Figure S-5: Analysis of specificity of ARTS compared with ARTS-R1 with different cell lines.

A) Analysis of specificity of the anti-CD3r aptamer in the ARTS compared with ARTSR1 control in the absence (black line) and presence of $500 \mu \mathrm{M}$ ATP (red line) with

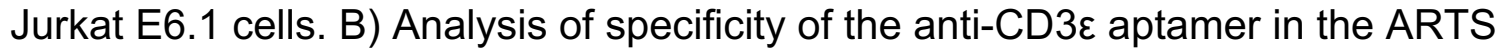
compared with ARTS-R1 control in the absence and presence of $500 \mu \mathrm{M}$ ATP with

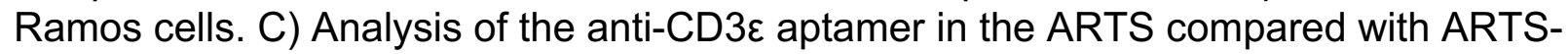
$\mathrm{R} 1$ control in the absence and presence of $500 \mu \mathrm{M}$ ATP with CA46 cells. D) Overall binding ratio using ARTS-R1 as background signal comparing Jurkat E6.1 cells to Ramos and CA46 cell lines. All constructs were prepared for the assay by heating at $95^{\circ} \mathrm{C}$ for 5 mins to denature undesirable secondary structures and then cooled to $25^{\circ} \mathrm{C}$ for 30 minutes. Next, $75 \mu \mathrm{L}$ of the molecule, final concentration $100 \mathrm{nM}$, was incubated with $75 \mu \mathrm{L}$ of $1 \times 10^{5}$ Jurkat E6.1, Ramos or CA46 cells for one hour. $500 \mu \mathrm{M}$ ATP was added to respective samples and similar volume of CSB buffer was added to the other samples. Binding of each aptamer was analyzed using flow cytometry by counting 5000 events. As a positive control, Jurkat E6.1 cell lines were incubated with $5 \mu \mathrm{L}$ of 25

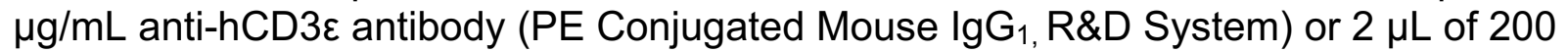
$\mu \mathrm{g} / \mathrm{mL}$ isotype control (PE Mouse $\lg _{1}, \mathrm{~K}$, BD Biosciences) for 30 minutes on ice, followed by a one-time wash with $2 \mathrm{~mL}$ of RPMI-1640 medium and reconstituted in 250 $\mu \mathrm{L}$ RPMI-1640 medium. Binding events were monitored in FL1 Green $(515-545 \mathrm{~nm})$ for the aptamer and in FL2 Yellow (565-605 nm; 564-606 nm) for the antibody, counting 5000 events using flow cytometry. 

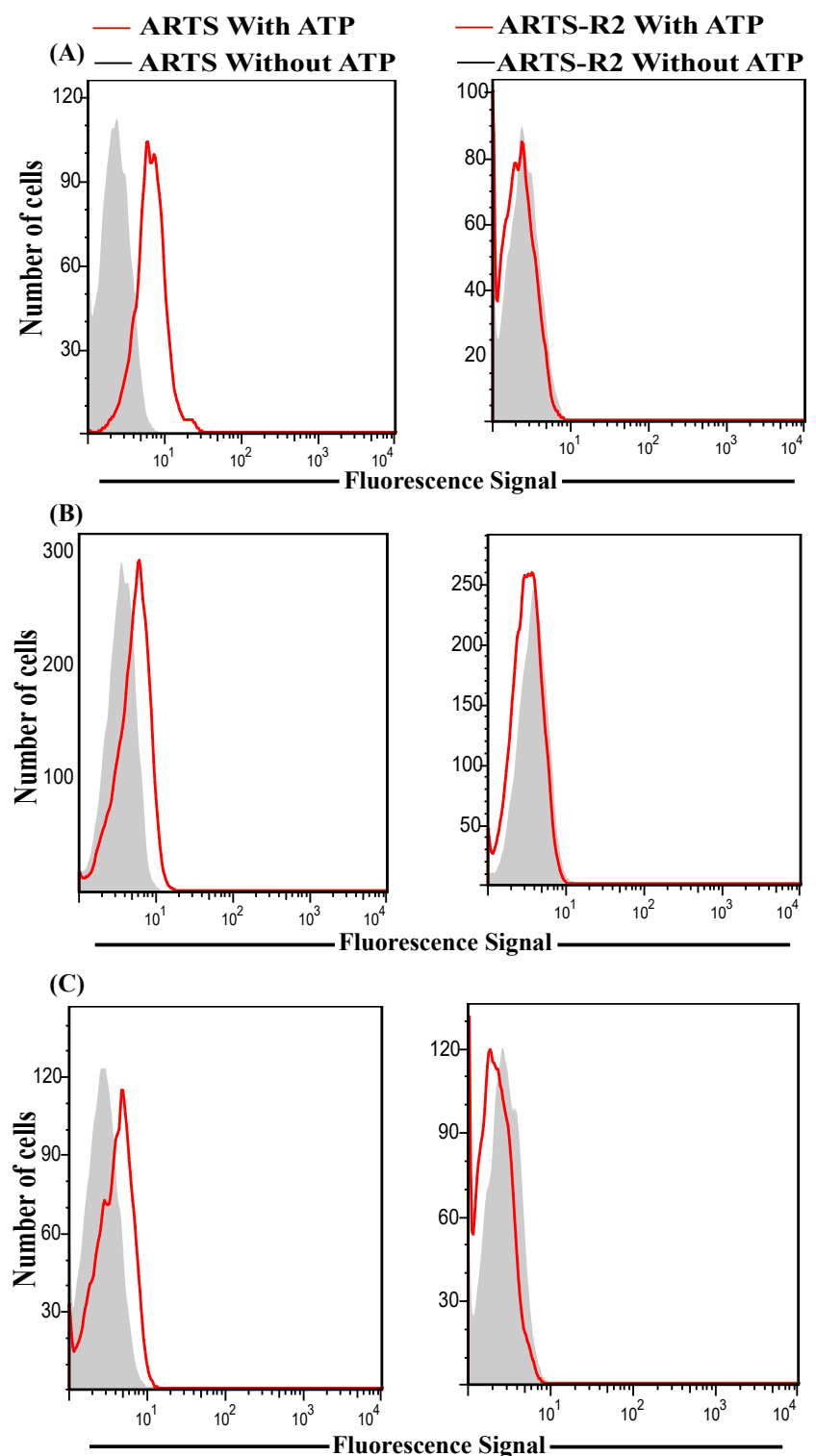

(D)

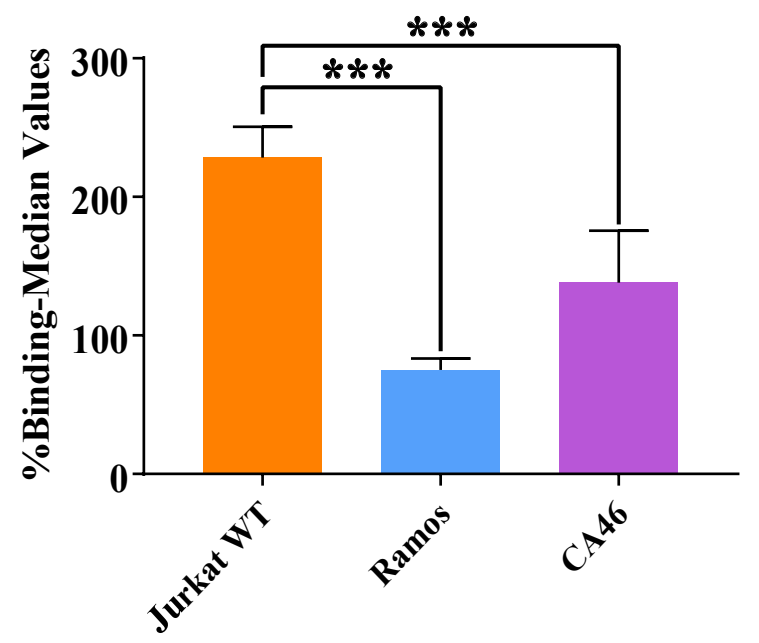


Figure S-6: Analysis of specificity of ARTS compared with ARTS-R2 with different cell lines.

A) Analysis of specificity of the anti-CD3r aptamer in the ARTS compared with ARTSR2 control in the absence (black line) and presence of $500 \mu \mathrm{M}$ ATP (red line) with

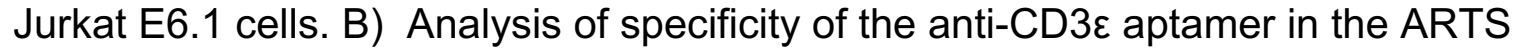
compared with ARTS-R2 control in the absence and presence of $500 \mu \mathrm{M}$ ATP with

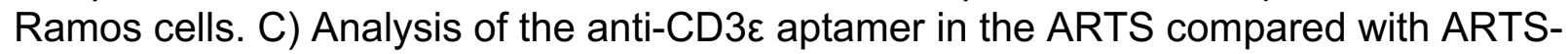
R2 control in the absence and presence of $500 \mu \mathrm{M}$ ATP with CA46 cells. D) Overall binding ratio using ARTS-R2 as background signal comparing Jurkat E6.1 cells to Ramos and CA46 cell lines. All dimers were prepared for the assay by heating the dimers at $95^{\circ} \mathrm{C}$ for 5 mins to denature undesirable secondary structures and then cooled to $25^{\circ} \mathrm{C}$ for 30 minutes. Next, $75 \mu \mathrm{L}$ of the construct, final concentration 100nM, was incubated with $75 \mu \mathrm{L}$ of $1 \times 10^{5}$ Jurkat E6.1, Ramos or CA46 cells for one hour. $500 \mu \mathrm{M}$ ATP was added to respective samples and similar volume of CSB buffer was added to the other samples. Binding of each aptamer was analyzed using flow cytometry by counting 5000 events. As a positive control, Jurkat E6.1 cell lines were incubated with $5 \mu \mathrm{L}$ of $25 \mu \mathrm{g} / \mathrm{mL}$ anti-hCD3 $\varepsilon$ antibody (PE Conjugated Mouse $\lg _{1}, \mathrm{R} \& D$ System) or $2 \mu \mathrm{L}$ of $200 \mu \mathrm{g} / \mathrm{mL}$ isotype control (PE Mouse $\lg _{1}, \mathrm{~K}, \mathrm{BD}$ Biosciences) for 30 minutes on ice, followed by a one-time wash with $2 \mathrm{~mL}$ of RPMI-1640 medium and reconstituted in $250 \mu \mathrm{L}$ RPMI-1640 medium. Binding events were monitored in FL1 Green $(515-545 \mathrm{~nm})$ for the aptamer and in FL2 Yellow (565-605 nm; 564-606 nm) for the antibody, counting 5000 events using flow cytometry. 